\title{
Designing Pedagogy Against Architectural Iconicity
}

\author{
JASON F. CARLOW \\ American University of Sharjah
}

\begin{abstract}
When designing buildings within the cultural and socioeconomic context of Dubai, it is necessary to consider the propagation of iconic, Neo-orientalist architecture. This paper seeks to address several issues surrounding the ethics of iconicity within the pedagogical agenda of an architectural design studio. In formulating a fifth year, undergraduate architectural design studio focused on high-rise tower typology in Dubai, several questions became important to the framework of the studio: How could the students in the course better understand the proliferation of iconic architectural forms in Dubai and other rapidly developing MENA cities and strategize a methodology for designing in response to that context? What are the regulatory and socio-economic incentives driving the construction of iconic buildings, inspired by both Western and Neo-orientalist styles in Dubai that students should be aware of? When designing a building envelope for an extreme climatic environment, how can one eschew symbolic references and use the skin as a starting point in the formation for unit planning, program distribution and overall building form?
\end{abstract}

\section{ICONICITY AND GLOBAL CAPITALISM}

The design studio, entitled "Thick Skins," was conducted to discover a more appropriate mode of design for high-rise towers in the Dubai context while avoiding the exploitation of architectural uniqueness or innovation for the sake of iconicity. Appropriateness in the context of the studio had to do with a critique of superficial, decorative symbolism and the importation of architectural building types from other cultures that don't sensitively respond to the extreme climate conditions of the Gulf region.

Twentieth-century architecture in Dubai reveals a steady progression toward the iconic. ${ }^{1}$ The built environment of Dubai is complicated by a neo-patrimonial governmental structure combined with a large, heterogeneous foreign population and a significant dependence on foreign capital. This combination of factors has incentivized iconic architecture at the expense of ecological sustainability and the establishment of a genuine urban identity. "The emphasis on the iconic, from the scale of the individual elements to man-made islands, represents a dominant tendency in the architecture of Dubai. Speculation supports growth in the real estate and construction industries, creating demand for visually arresting icons to attract the attentions of individual and institutional investors." ${ }^{2}$
Within the context of rapidly developing cities in the Gulf Region, neo-orientalist architecture applied to high-rise buildings is often used as a tool to impact the societal reception of iconic architecture for economic reasons. Leslie Sklair argues that the creation of iconic buildings, iconic spaces and urban megaprojects make capitalist hegemony, "the everyday expression of the power of the dominant class," more clearly visible. ${ }^{3}$

As opposed to architectural innovation in the pursuit of creating iconicity, which could be used as an agent to further empower the ruling class to control capital, the Thick Skins studio encouraged innovations in tower architecture to define a new tower type, determined by the performance of the building envelope that could be applied to many buildings, not just a singular iconic structure. A guarded aversion to iconicity in a studio focused on tower design seeks to avoid two ethical problems associated with global capitalism, polarization of class and ecological unsustainability. ${ }^{4}$ The studio brief asked students to focus on a façade system, adaptable to all buildings within a climatic region, (high-rise, mid-rise and low-rise) that forced students to think beyond the singular, architectural solution. The absence of a definitive architectural site for the studio was central to addressing the issue of tower type versus specific tower. Site was instead defined by local conditions such as climate, economy, and culture versus a specific street address, neighborhood or view.

\section{STUDIO BACKGROUND}

The Thick Skins studio sought to explore innovations in the overall organization and design of high-rise, mixed use towers with a specific focus on performative façade systems. Whereas the term "performative façade" typically refers to energy saving capacities for the building, the definition of performance in the Thick Skins studio could be more broadly interpreted by the students. Performance, within the context of the studio, could relate to a number of categories, including energy saving, ecological, societal, economic, and production. Students were encouraged to formulate schemes that performed well across multiple categories.

The students' design work built off of a series of case study exercises designed to build expertise in local conditions and architectural precedents from around the world. To better acquaint students with the local context of high-rise development, the studio carried out a case-study of existing and proposed towers in Dubai and other cities within the Gulf 
region. This initial case study served to find examples of performance-driven façade systems and also as a critique of buildings that used superficial cultural references or decoration as a design driver at the expense of building performance. Studio participants studied examples of high-rise buildings that have been developed during Dubai's rapid growth over the last two decades to gain a deeper understanding of the building code regulations, economic concerns, global production networks and cultural factors that contribute to building form. Through critical analysis, the studio created a reference catalog of floor plans, circulation cores, façade details, program diagrams, and key aspects of the building regulations to uncover opportunities for design innovation and improvement.

The studio established a critical stance toward buildings that are guided by generic modes of design and production and buildings that have little relationship to the extreme climatic conditions of the UAE and Gulf region. The studio also challenged building form that is primarily driven by developers' desires for superficial cultural aesthetics and/or corporate iconicity to the detriment of building performance. Looking outside of the region, students gathered precedent examples of buildings from around the world, especially from tropical climates, built over the course of the twentieth and twenty-first centuries to examine, analyze and formulate architectural strategies.

By combining a comprehensive set of case studies with a set of explorative design exercises, students worked to produce contextually responsive, better integrated, architectural prototypes. As the studio name suggests, design research started with the skin of the building and worked inward through various scales to thicken the peripheral zone and rethink the overall architectural form and organization. While the outer skin or façade system of a high rise tower is typically the site for the addition of decoration that contains cultural or regional symbolism, it is perhaps ironic to situate a design studio positioned against iconicity and cultural references in the traditional architectural site of decoration and symbolism, the façade. With the use of digital design tools and techniques, this atypical approach toward building design aimed to create prototypes for a better performing building envelope, but an architecture with value that is more than skin deep.

\section{ICONICITY AND ENVIRONMENTAL CONTEXT}

Many examples of high-rise office and residential buildings in Dubai do not differ significantly from those found in other global cities. With the rapid influx of investment in the Gulf region starting in the 1980's, the globally established construction method of exposed glass curtain walls were employed extensively in almost every commercial high-rise building façade in the Gulf. ${ }^{5}$ Why should an office building in Dubai resemble or imitate an office building in Frankfurt or
London? Reliance upon mechanical air conditioning systems to cool buildings enclosed within a tight hermetic envelope are common in the UAE and increases the region's reliance on fossil fuels. Little learning or knowledge from traditional or vernacular architectural examples is applied to many high-rise buildings in the UAE. The studio sought to create buildings that respond better to local climatic conditions.

During the rapid development of Dubai and other Gulf cities over the past decades, many urban areas exhibit a strange architectural eclecticism comprising a jumbled mix of building styles. Banal background buildings are punctuated with an assortment of incongruent towers that seek to establish iconic status through different stylistic means. In most cases, both extremes of Dubai's skyline, the iconic and the banal, are built in response to imported architectural types with little consideration of or regard for local conditions. Iconic towers are often cheap knock-offs of familiar architectural tropes, modeled after skyscrapers imported from other cities, cultures, climates and eras of design. According to Kevin Mitchell, "investor-driven markets seem to breed the need for the extraordinary that results in a cacophony of the outrageous." ${ }^{16}$ Overly standardized stock buildings employ mass production to maximize developer profits by minimizing design considerations and variation.

In terms of the banal, the movement away from one-off construction methods to industrially standardized units is not new. The mass production of architectural elements and standardization of building components and techniques dates back to the early 19th century. Though as leading architects, developers and visionaries sought to adopt the standardized, production-line techniques of the Ford automobile factory in the 20th century, variation and site-specificity was often reduced or completely lost. Mass production and standardization are still regarded by architects and developers as a solution for rapid growth and bigger profits. Overly standardized models of design and construction have had a negative impact on rapidly developing cities world-wide. The Thick Skins studio brief asked students to re-evaluate the various environmental impacts of this standardization in terms of social, economic and ecological repercussions and seek to invent better architectural alternatives through performance-driven variation.

\section{STUDIO METHODOLOGY}

Using a blend of traditional and computational design techniques, the studio endeavored to develop innovative façade systems that work within code-based limitations. Students were asked to not only consider the outward appearance of buildings, but also their performance in terms of programmatic, material and environmental factors. The studio challenged the use of parametric or digital design tools to negotiate form or aesthetics alone. Instead, students took a more holistic stance on digital design to consider the building aesthetics, façade performance and site specific production. 
The studio sought to tie design investigations more directly to local context. Students worked, at first, within the constraints of local building codes in order to better understand the close relationship between form and regulations. Eventually, through design research, some students proposed alterations or amendments to existing building codes. The studio also looked into the use of pre-manufactured building components. As the UAE's manufacturing industry has been built up over recent years to deliver locally produced architectural materials and components, students sought to find modes of construction that are site specific in that they relate to regional resources and industrial strengths. Therefore, the studio looked beyond mere design of elements and into the entire cycle of construction including material production, and module fabrication, transportation, installation and eventual reuse or demolition.

Students explored façade design with various materials, traditional and experimental. Through the investigation of a similar problem through various material explorations, students came to understand how inherent characteristics of material construction have an impact on fabrication and form.

Standardized facades in climatically extreme climates are problematic. The relatively heavy reliance of buildings in the Middle East on air-conditioning systems is partly due to the inability of façade systems to block solar radiation or increase the potential for natural ventilation on the surface of buildings. Mitchell argues that "the stringent measures necessary to regulate the building industry [in terms of energy performance] would almost certainly adversely affect short-term profit margins, and thus may jeopardize a reputation built upon neo-liberal economic policies and laissez-faire capitalism."7 As policies toward sustainability are hard to maintain in Dubai due to the transient population and dependence on foreign investment and capital, energy efficiency, solar shading and ecological sustainability did play a large thematic role in the studio. Students were encouraged to use solar shading studies to work back and forth through formal design and analysis to make façade performance an important design criterion.

\section{CASE STUDY RESEARCH}

The first part of the studio was dedicated to case study research of architectural precedents and local building regulations. The following sub-categories were examined:

A. Local Built-form/Building Code Research: Students researched Dubai's built form and building codes through reading, field study and analysis. Students documented critical aspects of building and planning codes through drawing, modeling and image collection. Efforts from the built form and code research were compiled into a studio reference catalog for use during the course of the semester.

B. Technology and Terminology: Students gathered information on solar shading and façade systems from web-based sources as well as from books, articles and journals to better understand the way that building facades are designed, how they perform and how they are manufactured.

C. International precedents: This third case study assignment focused on a select group of high-rise building precedents, built outside of the UAE, to better understand various types of high density housing and office typologies. Students collected images and produced drawings and diagrams about each building in order to better understand building envelope, planning, circulation, unit repetition and structural organization. The studio produced analytical diagrams that uncovered rules and patterns associated with each given precedent. The exercise will not sought to better understand physical and spatial patterns of organization in high-rise building types, but asked students to consider the social and domestic repercussions of built form.

\section{BUILDING CODE ANALYSIS}

One student team was assigned to investigate the relationship between building code and building form in Dubai. The complex public/private relationship that has evolved in the development of Dubai and other GCC cities over the last decades has yielded a piecemeal building code for the emirate of Dubai. A comprehensive building code for the entire emirate is replaced with a suite of separate building codes for sections of the city developed by various private developers. Height limitations, façade fenestration ratios and provisions for stylistic cultural references vary from district to district, depending on the developer.

Certain aspects within the building code were discovered that seemed to incentivize iconicity. Tops of buildings are unregulated. According to the Dubai Municipality Building Code Regulations there are certain parts of buildings that are exempt from height calculations:

g. Following parts of Buildings that are allowed to exceed the height:

1. Ornamental elements in general terms including minarets, domes, beautification and folkloric towers.

2. Chimneys and smoke disposal ducts, elevators chutes, staircases, radio and television antennae, cooling towers, pergolas, helipads and parts of the roof parapet walls.

3. Billboard towers, provided that they shall be consistent with terms and conditions applicable in this respect by the Department concerned.

4. In case of trusses and domes, both the maximum building height and the maximum net internal height, may be exceeded in order to cope with structural and beauty requirements. ${ }^{8}$ 


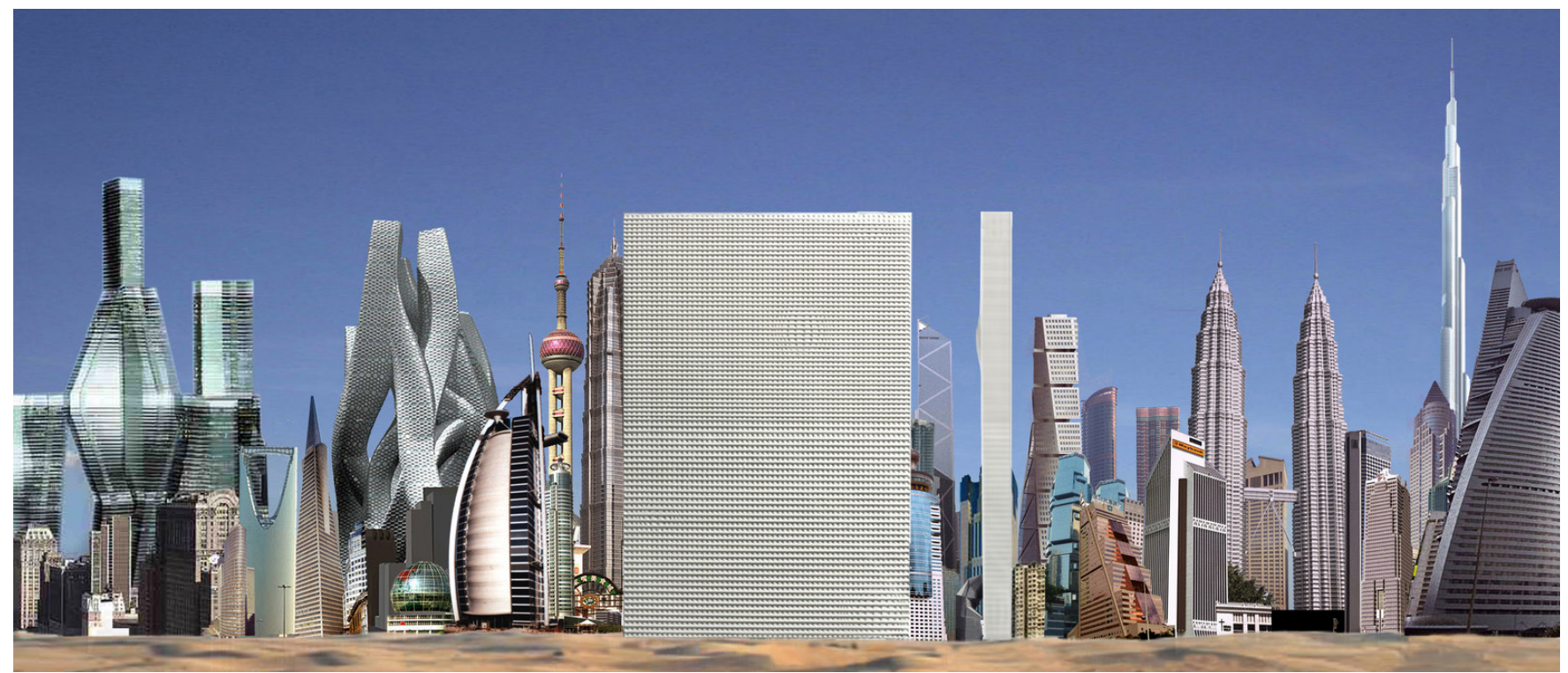

Figure 1: The Renaissance Dubai Tower proposal by OMA developed for a architectural competition in 2006 depicts the project juxtaposed with a cacophony of iconic towers from across the globe. Image downloaded from http://oma.eu/projects/dubai-renaissance in October 2017.

\section{A SPECTRUM OF ANTI-ICONIC TO OVERTLY ICONIC BUILDINGS}

The ethical guidelines of the studio were related to building "appropriateness" and thereby situated around performance. As mentioned earlier the definition of performance was largely left to the students and based on case study research that analyzed a series of local and international architecture precedents. The studio brief asked student participants to consider not just ecological or energy use or ecological sustainability, but a broader definition of performance that includes social, political, material and manufacturing factors. The case study exercise was particularly focused on interrogating examples of buildings that exhibited superficial iconography, pattern or image to reconstruct a false historical narrative. By critically analyzing a series of local and international examples of buildings and façade systems, the studio was able to form a catalog of various types of ethical or appropriate performance and develop a position again skin-deep iconic performance.

The case study research and subsequent class presentations and discussions revealed a number of building precedents in Dubai and the region which fall into a spectrum of responses to the iconic. The following are a few of the examples and the terms developed and used by the studio to classify their response to the iconic. They are organized from the most adversely reactive to the iconic to the most sympathetic.

\section{THE ANTI-ICON}

OMA's proposal for the Dubai Renaissance tower in 2006 (Fig. 1) served as an extreme form of critique to the overly iconic city-scape of high-rise buildings that has come to represent cities in the Gulf region. By falling back upon a reductive, international style building form and façade, the building rejects the project of iconicity driven by Dubai developers' desires to create a world-class skyline. The project is described by OMA on the company's website as follows:

"So far, the 21st century trend in city building leads to a mad and meaningless overdose of themes, extremes, egos and extravagance... The ambition of this project is to end the current phase of architectural idolatry - the age of the icon - where obsession with individual genius far exceeds commitment to the collective effort that is needed to construct the city...Instead of an architecture of form and image, we have created a reintegration of architecture and engineering, where intelligence is not invested in effect, but in a structural and conceptual logic that offers a new kind of performance and functionality."

However, by resorting to a Western, high-modern mode of design for the building's form and skin, the project avoids the use of Neo-orientalist cultural references but also seems to ignore important local environmental and climatic contexts that could improve the overall performance of the building.

While OMA's Renaissance Tower proposal operates as a form of architectural critique to the overly designed, jumbled iconic language of the contemporary GCC metropolis, it provides an example of what the studio was struggling to avoid: the importation of a foreign mode of design thinking for the Dubai context that because of its relatively thin façade, would rely heavily on energy intensive, mechanically driven, building systems.

\section{PERFORMANCE CLOAKED AS SYMBOLISM}

The case study exercise uncovered the use of Neo-Orientalist symbolism cloaked as environmental performance and vice 


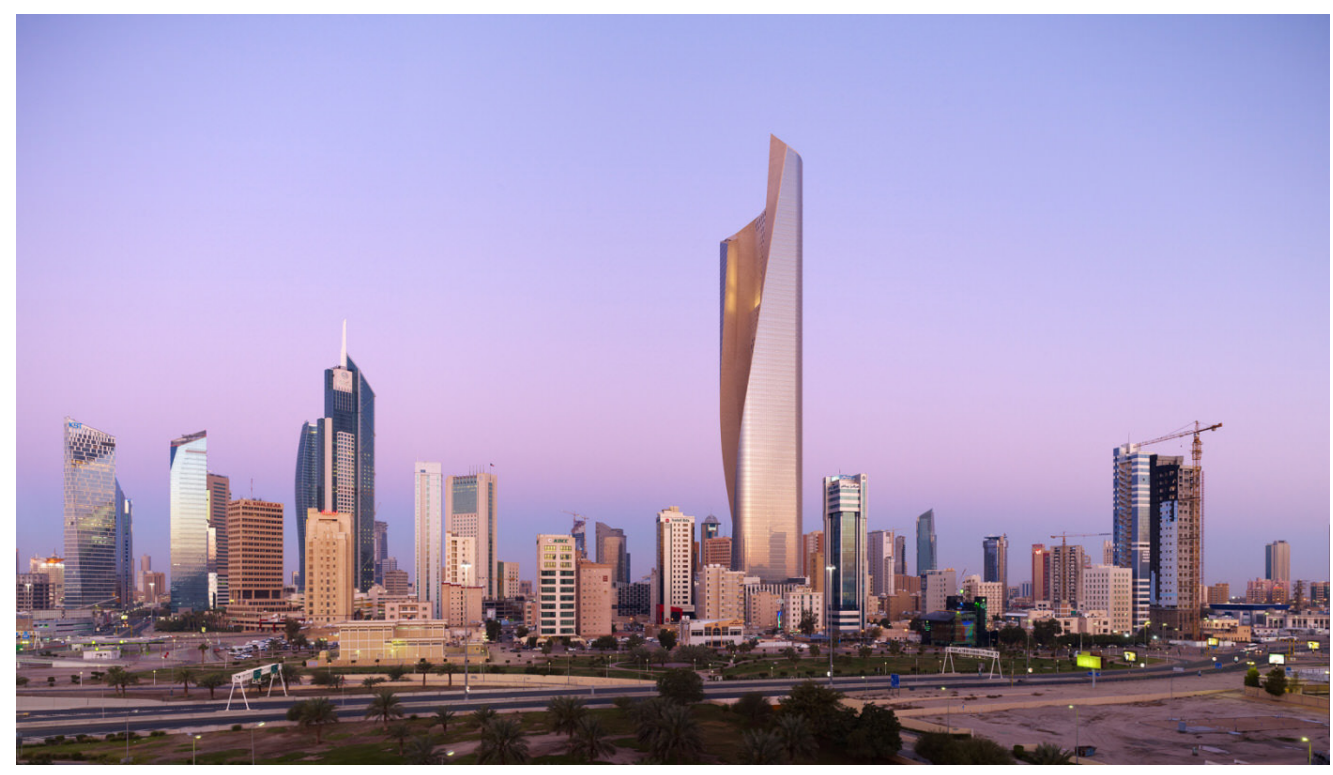

Figure 2: The Al Hamra Tower in Kuwait City by soM Architects. Image downloaded from http:// www.som.com/projects/ al_hamra_tower_structural_engineering in October 2017.

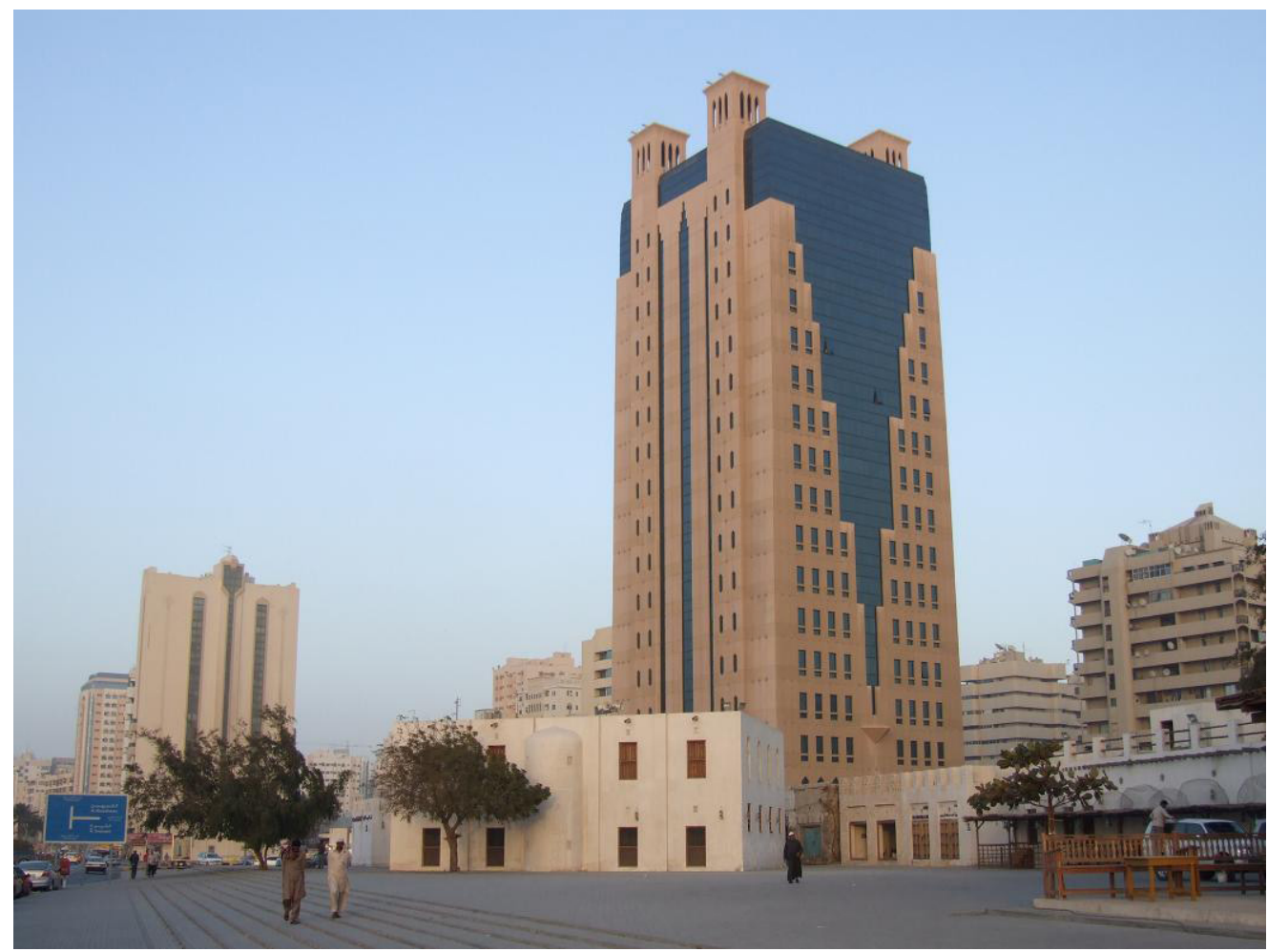

Figure 3: A high rise building in the Emirate of Sharjah, next to Dubai, that uses traditional (nonfunctional) ventilation towers as decorative elements. Photograph taken in February 2008 by Brandt Maxwell.

versa. For example, in its project description of the Al Hamra Tower in Kuwait City, (Fig. 2) the global architecture firm, SOM explains that the form of the building is a combination of performative concerns

mixed with a locally inspired, orientalist cultural reference. "A desire to maximize views of the Arabian Gulf while minimizing solar heat gain inspired the building's asymmetrical form, which calls to mind the traditional robes worn by Kuwaitis."10

The studio critique for this type of building revealed a motivation by the architects to give the developer a building form that could respond to the creation of a local identity while retaining a responsible end-goal of building performance. The balancing act of combining neo-orientalism symbolism with energy efficiency led to the question: to what extent is the iconic form of the building compromising the ecological performance and vice versa? In this case study example the architects' metaphorical narrative of the building resembling traditional local garb suggests that the symbolism of the building served an important performative task in the marketing the building to the developer by the architect, or the developer using the building as a marketing tool toward the public.. 


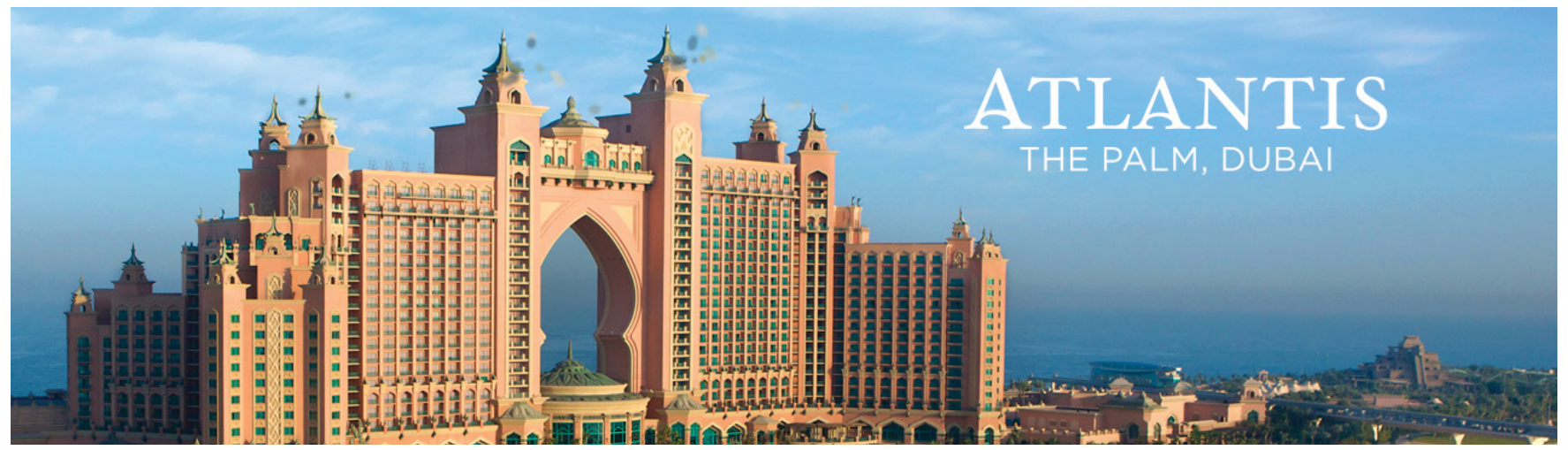

Figure 4: The Atlantis Hotel on the Palm Island resort district in Dubai. Image downloaded from http://itsaboutdubai.com/places/hotels/ overview-atlantis-the-palm-dubai-review/ in October 2017.
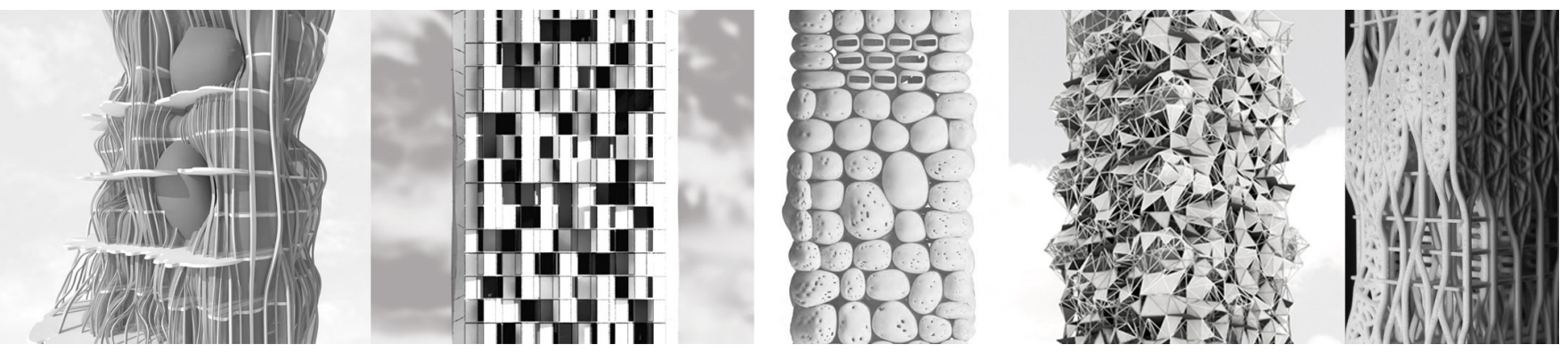

Figure 5: Student projects for the Thick Skins design studio. Images by Nafaa Malik, Shahad Kashmiri, Yasmin Hamad, Rasha Saffarini, Mohammad Alkhazendar and Nishita Vinodrai.

\section{SYMBOLISM CLOAKED AS PERFORMANCE}

There are a number of buildings recently constructed in the UAE region that have used fake ventilation towers to create traditional roof-scapes and conceal rooftop elevator equipment rooms (Fig 3). Wind towers were used in earlier decades and centuries across the MENA (Middle East and North Africa) region for natural ventilation to vernacular low-rise buildings. Fake wind towers and decorative elements construct a false symbolic language around the concept of sustainable energy-use performance that inappropriately attempts to link contemporary buildings to the traditional buildings of the region.

\section{OUTRIGHT SYMBOLISM}

On one extreme of the spectrum of buildings from the symbolic to the anti-iconic were examples of towers that openly employ Neo-orientalist symbolism or decorative elements without any value beyond the formation of an image. There are many buildings in Dubai and the region that use overtly symbolic architectural references to local cultural. There are some high-rise buildings that use direct references to Arabic architecture such as domes, pointed arches, mashrabiya screens and Islamic patterns. There are also examples that have references to more generic aspects of local culture, such as the sail inspired forms of the Burj Arab and the National
Bank of Dubai Headquarters tower or buildings that resemble Bedouin tents or desert sand dunes.

The development of global tourism as one of the UAE's main economic sectors increases the tendency towards regional cultural symbolism and decorative kitsch. The Atlantis Hotel on the Dubai Palm (Fig 4) has become one of the most promoted architectural landmarks of Dubai. The project overtly uses symbolic motifs and references of Arabic architecture to provide it with a visual identity that attempts to situate it within the culture of the UAE and the Gulf region. It's interesting to note that the Atlantis Hotel on Paradise Island in the Bahamas has a very similar architectural massing to its UAE cousin, but makes use of more neo-classical motifs and ocean inspired architectural details to situate it within its Caribbean context.

\section{CONCLUSIONS}

There is a clear argument that could be made in that iconicity itself could be considered a performative characteristic that could add economic or socio-political value to a project in a speculative city like Dubai. In response to the problems of urban identity and class repression that are associated with the proliferation of iconic architecture, the studio was structured around an ethical imperative to find a way to 
counter the "Icon Project," in the words of Sklair. Cultural or image-based performance was countered by the search for a multi-faceted performance. In a sense, the building systems that perform in multiple ways were assessed to have more value than singular instances of performance. Therefore a self-ventilating façade system that also provided space for communal activities would be deemed superior in overall performance than a fake-wind tower that only visually connected the building to vernacular traditions.

The studio outcomes, developed as a series of comprehensive tower proposals yielded innovative projects (Fig 5). If presented as singular towers inserted into the awkwardly heterogeneous architectural context of Dubai, they could be misunderstood as additional attempts to create iconic buildings. To conceptualize, design and present projects as environmentally sensitive and culturally critical building envelope systems that could be applied to many types of buildings was an attempt to create an appropriately ethical, architectural type for the region.

\section{ENDNOTES}

1 Kevin Mitchell, "From the intimate to the iconic: Architecture in Dubai from 1967 to 1997," In Dubai: Growing through Architecture, ed. George Katodrytis, (London: Thames \& Hudson), (In press).

2 Kevin Mitchell, "In What Style Should Dubai Build?", in Dubai: Stadt as dem Nichts, ed. Elisabeth Blum and Peter Neitzke, Basel; Birkhauser Verlag AG, 2009), 138.

3 Leslie Sklair, The Icon Project: Architecture, Cities, and Capitalist Globalization, (New York: Oxford University Press, 2017), 3.

4 Leslie Sklair, The Icon Project: Architecture, Cities, and Capitalist Globalization, 9.

5 George Katodrytis, "Performative Urbanism: An Emerging Model of the Gulf", in Architectural Design, UAE and the Gulf: Architecture and Urbanism Now, ed. George Katodrytis and Kevin Mitchell, no. 233, (Jan/Feb 2015), 123.

6 Kevin Mitchell, "In What Style Should Dubai Build?”, 139.

7 Kevin Mitchell, "Dubai, UAE", in Architecture and Globalisation in the Persian Gulf Region, ed. Murray Fraser and Nasser Golzari, (Farnham,Surrey: Ashgate Publishing Limited, 2013), 161.

8 "Except from the Dubai Building Code Regulations for Construction," last modified February 2004, https://docslide.net/documents/dubai-municipalitybuilding-code-regulations-construction-specifications.html

9 “Dubai Renaissance," http://oma.eu/projects/dubai-renaissance

10 "Al Hamra Tower," http://www.som.com/projects/al_hamra_tower 